\title{
Maturidade Organizacional em Inteligência Competitiva - O Caso de uma Instituição Financeira Brasileira
}

Organizational Maturity in Competitive Intelligence - The Case
of a Brazilian Financial Institution

\section{Leonel Cezar Rodrigues}

Professor do Programa de Pós-Graduação de Administração. Universidade Nove de Julho - UNINOVE. São Paulo, SP. Brasil.

E-mail: leonelcz@gmail.com

\section{Júlio Cesar Volpp Sierra}

Programa de Pós-Graduação de Administração. Universidade Nove de Julho - UNINOVE. São Paulo, SP. Brasil.

E-mail:volpp@uol.com.br

\section{Waldir Rechziegel}

Programa de Pós-Graduação de Administração. Universidade Nove de Julho - UNINOVE. São Paulo, SP. Brasil.

E-mail: rechziegel@hotmail.com

\section{Resumo}

Este estudo tem como objetivo geral caracterizar e identificar o grau de maturidade em uso de Inteligência Competitiva (IC) de uma instituição financeira em um país emergente, segundo modelo de maturidade consagrado na literatura. Para realização deste trabalho, o método escolhido foi o estudo de caso único. Foram realizadas quatro coletas de dados em áreas distintas da organização estudada: Marketing, Segurança Física, Relações Internacionais e Gestão de Riscos de Ativos. Os principais resultados indicam que duas áreas apresentam maturidade em Nível 1 - Informal, e outras duas áreas apresentam maturidade em Nível 2 - Formal. As principais conclusões apontam para a coerência dos critérios e elementos que sustentam a lógica do modelo de maturidade testado. Demonstram ainda que na organização estudada a IC é descentralizada e que o modus operandi da IC nessa organização é intuitivo e avançado para seu nível de maturidade.

Palavras-chave: Inteligência Competitiva. Maturidade em Inteligência Competitiva. Modelo de Maturidade.

\section{Abstract}

This study aims at characterizing and identifying the degree of maturity in Competitive Intelligence (CI) of a financial organization from a developing country, abyding by a maturity model in the literature. To do this research, the chosen method was the case study. Data were collected among 4 distinct áreas of the organization: Marketing, Physical Security; International Relations; and Risk management. Main results indicate that two áreas show maturity in CI, level 1 - Informal. The othe two show degree of maturity in $\mathrm{CI}$, level 2 Formal. Conclusions of the study support coherence of criteria and elements that bolster the logic of the selected model and the decentralized structure of $\mathrm{CI}$ in the studied organization, showing, in an yet intuitive way, to hold an advanced CI operating model.

Keywords: Competitive Intelligence. Maturity in Competitive Intelligence. Competitive Intelligence Maturity. Maturity Model. 


\section{INTRODUÇÃo}

A exigência do consumidor quanto à satisfação plena de suas necessidades e interesses estão em processo de ampla mudança (DAVIS; STEPHENSON, 2006). Dados da Pesquisa de Inovação Tecnológica (PINTEC), do IBGE, mostram que a velocidade da mudança no ambiente competitivo requer das organizações competências de flexibilidade organizacional para adaptarem-se, de maneira ágil e constante, aos novos cenários. De um lado, os mercados consumidores das economias em desenvolvimento, ou emergentes, batem recordes de transações comerciais a cada ano e novos consumidores entram no mercado devido à melhoria em seu poder aquisitivo. De outro lado, em economias desenvolvidas, como as da Europa e a dos Estados Unidos, novos hábitos de consumo e novas necessidades devem ser identificados e satisfeitos. Para responder às necessidades de ambos os tipos de mercado, é necessário às empresas capacidade de inovar. (PINTEC, 2011)

Há uma reconhecida tendência ao longo dos setores econômicos, na qual as organizações, a cada dia, tendem a basear suas decisões e formulam as estratégias a partir da análise científica das informações (DAVIS; STEPHENSON, 2006). Os autores identificaram em sua pesquisa mundial, que cada vez mais, os executivos de grandes e médias empresas deixam de lado o velho hábito de administrar por instinto, para administrar baseados em informações processadas por sistemas de Tecnologia de Informação altamente sofisticados.

Obter informações de modo sistêmico e aplicado aos interesses específicos e estratégicos da organização diz respeito à Inteligência Competitiva. Com origem na atividade militar e de segurança das nações (PRESCOTT; MILLER, 2002), a inteligência competitiva foi trazida para o âmbito da Administração, como uma evolução funcional das atividades dos Sistemas de Informação (GOMES; BRAGA, 2006). Como campo de estudo, no entanto, a Inteligência Competitiva é uma área ainda incipiente, especialmente no Brasil. Dessa forma, Inteligência Competitiva merece uma definição para entendimento dos propósitos deste trabalho.

Segundo a Society of Competitive Intelligence Professionals (SCIP), Inteligência Competitiva consiste em um programa sistemático e ético para reunir, ana- lisar e administrar informações externas que podem afetar planos, decisões e operações de uma empresa (SCIP, 2010). A Associação Brasileira dos Analistas de Inteligência Competitiva (ABRAIC) define Inteligência Competitiva como atividade voltada para o ambiente competitivo que busca a manutenção ou desenvolvimento de vantagem competitiva. (ABRAIC, 2010)

As empresas brasileiras não são exceções dentro do cenário competitivo descrito mais acima e precisam, portanto, buscar informações que orientem suas operações (RODRIGUES; RICCARDI, 2007). O sucesso empresarial cada vez menos depende da sorte ou da intuição pessoal de executivos acerca das possíveis tendências de um negócio, como já apontado anteriormente. De uma forma ou de outra, as empresas acompanham diariamente a atuação dos seus concorrentes, seja de maneira informal, ou através de um sistema organizado. Uma pesquisa recente, contida na obra de Rodrigues e Riccardi (2007) demonstra que esse acompanhamento quase sempre é realizado por pessoas da organização, geralmente ligadas à área de marketing, de maneira informal ou formalizada. A maior, ou menor sistematização, ou formalização do uso da Inteligência Competitiva é pelos autores tratada como nível de maturidade no uso da Inteligência Competitiva.

Os autores caracterizam a Inteligência Competitiva no nível de maturidade informal, como sendo incipiente, sem norma ou estrutura definida. Já no nível formal, a Inteligência Competitiva tem um sistema estruturado e normatizado. No nível disciplinado, o sistema está incorporado à instituição e, é praticado. O próximo nível, controlado, é caracterizado pelos processos de avaliação de desempenho do sistema. E, por fim, o quinto nível, otimizado, é caracterizado pela ampliação da abrangência do sistema e seu aperfeiçoamento.

\subsection{Problema da Pesquisa}

As organizações possuem, de alguma maneira, um sistema de captação, processamento e disseminação da informação, seja ele formal ou informal. Isso porque, cada vez mais, a eficiência do processo decisório nas organizações depende do acesso e disponibilização de informações. 
No caso da organização objeto dessa pesquisa, apesar de operar num setor (setor bancário) em que a análise de entorno e movimentações da concorrência é crucial, seu sistema de Inteligência Competitiva parecer ser invisível ou inexistente. Na pesquisa preliminar sobre a instituição, não foi identificada uma área ou departamento central dedicado à Inteligência Competitiva, mas apenas duas áreas que possuem gerências formalmente dedicadas à Inteligência Competitiva. Dada a importância contextual da Inteligência Competitiva para as organizações, em especial as organizações de setores de alta competitividade, tais como o setor bancário, imagina-se que o desempenho seja uma função do acesso a informações de entorno de forma sistêmica. A organização selecionada é uma empresa centenária do setor bancário nacional, com um patrimônio líquido acima de $\mathrm{R} \$ 15$ bilhões. A organização está entre as cinco maiores instituições financeiras do país em volume de ativos totais.

Adicional à questão de acesso à informação, estão os produtos do sistema de Inteligência Competitiva, que são centrais à arquitetura de processos decisórios e de formulação de estratégias da organização. Esses produtos influenciam de várias formas a formulação das estratégias e as decisões internas, que repercutem diretamente sobre o desempenho do negócio. A utilidade dos produtos (que contém informações) pode variar de acordo com a experiência da equipe de IC e do grau de formalização dos processos de IC, isto é, do grau de maturidade em uso da IC. Pode-se inferir que o bom desempenho do negócio é uma função importante da maturidade em uso da Inteligência Competitiva.

Assim, supondo que, para a solução de seus problemas de desempenho, a organização selecionada lança mão de informações específicas para sustentar suas decisões e formular suas estratégias, este estudo tem como objetivo geral caracterizar o sistema de Inteligência Competitiva e identificar o grau de maturidade em uso deste sistema em uma instituição financeira. Para tanto, usa-se o modelo de classificação da maturidade em uso da IC de Rodrigues e Riccardi (2007).

\section{Antecedentes Teóricos}

Aborda-se aqui os conceitos e funções da Inteligência Competitiva, seus processos e usos, bem como os Níveis de Maturidade em uso da Inteligência Competitiva, obedecendo a um plano de revisão preestabelecido.

\subsection{Inteligência Competitiva - Conceitos e Funções}

Os pioneiros da IC no mundo dos negócios, originários de diversas organizações governamentais de inteligência, encontraram nelas um ambiente favorável às suas aptidões profissionais de inteligência para coletar e processar as informações de forma ética e legal. Os conceitos de inteligência que por muitos anos sustentaram as estratégias militares, agora poderiam ser utilizados para obter significativa vantagem competitiva em seus campos de operação. (GOMES; BRAGA, 2006, PRESCOTT; MILLER, 2002)

A herança militar que marcou a IC tem marcado a transição dessa atividade para a empresa, contaminando a opinião pública com distorções conceituais, relacionando o termo "inteligência" como espionagem, e informações confidenciais ou ilegais (PRESCOTT; MILLER, 2002). É importante elucidar que apesar de uma maior compreensão acerca do papel da IC nas decisões e na formulação de estratégias, que a IC na empresa não se fundamenta em atos de espionagem, roubo ou furto de informações. O objeto de informações da IC são fontes públicas e livres de dados e informações que podem ser usados, de forma independente de sua extensão. (FULD, 1995)

Sob o ponto de vista do conceito de IC, a Society of Competitive Intelligence Professionals (SCIP) define IC como um programa sistemático, contínuo legal e ético de reunir, analisar e distribuir informações externas a usuários, que sustenta os planos, decisões e operações de uma empresa (SCIP, 2007). Nessa mesma linha, Coelho et al. (2006) definem a IC como um processo sistemático de recolher, classificar, analisar, gerir e disseminar a informação sobre os ambientes competitivos do mercado concorrencial e organizacional. Utilizando-se de práticas éticas e legais, a IC deve ser integrada no processo de tomada de decisão para atingir as metas estratégicas da organização.

Combs (1992) define a IC como um processo de análise do posicionamento, desempenho, potencialidades e intenções estratégicas dos concorrentes e transforma a informação em conhecimento estratégico. 
O autor associa à atividade da IC o conhecimento estratégico, o que distingue a função e o papel da IC nos processos de negócio.

Apesar de pequenas variações, a função da Inteligência Competitiva é entendida pelos vários estudiosos de forma bastante uníssona, como sendo o processo de coleta, análise e distribuição de informações legal e eticamente obtidas, relativas ao entorno competitivo $e$ de comportamento do consumidor (FULD, 1995; SCIP, 2010; RODRIGUES; RICCARDI, 2007; PRESCOT; MILLER, 2002; COMBS, 1992; WEISS, 2002; TYSON, 2002), com o objetivo de sustentar os processos decisórios nas organizações.

Por fim, é importante notar que a construção de um sistema de IC numa organização é um processo social (PRESCOTT; MILLER, 2002). A cultura numa organização, sustentada pela IC é construída de forma paulatina. Primeiro, com o aprimoramento das qualificações relativas ao trato das informações, depois com a formação de redes de contatos pessoais e finalmente com a formalização dos mecanismos que permitem o fluxo adequado de informações.

\subsection{Processo de Inteligência Competitiva}

Na concepção de um sistema de IC, o processo sustenta a lógica que fundamenta a execução de suas atividades. Prescott e Miller (2002) afirmam que o fator fundamental para o sucesso do processo de inteligência é o atendimento das reais necessidades do usuário. Assim, a organização atua sob seu sistema de inteligência, garantindo sucesso no empreendimento. $\mathrm{O}$ uso de um processo formal de identificação das necessidades gerenciais é considerado uma das principais razões do sucesso da atividade de IC.

Os processos clássicos associados às atividades de IC foram primeiro propostos por Herring (1999). O autor aponta cinco estágios integradores dos processos da IC. No primeiro estágio - Planejamento e Direção - identificam-se as necessidades de inteligência a partir de necessidades básicas da organização. Essas necessidades vão orientar o plano e a execução das atividades de coleta de informação. No segundo estágio, as informações são coletadas criando a base de informações para as necessidades. No terceiro estágio, as informações são analisadas e processadas, gerando-se os produtos da IC. No quarto estágio, as informações são disseminadas para os usuários. E no quinto estágio procede-se ao monitoramento das atividades da IC e de seus resultados na organização.

Treverton (2001) acredita que a IC acontece de forma mais simplificada e não idealizada como em Herring (1999). Ele chama o seu do ciclo real de IC, que começa pela (1) coleta de dados de inteligência que por sua vez produz a (2) matéria prima da inteligência. As informações coletadas são (3) processadas e analisadas pelos expertos em IC. As informações fluem então para os responsáveis pela política que reagem àquelas informações gerando políticas e decisões ou criando tarefas complementares de inteligência, que (5) originam novas tarefas de inteligência.

Johnston (2005) descreve o sistema de IC como um sistema aberta de entrada, processamento e saída. O autor usa símbolos iconográficos (estoque, fluxo, conversores e conectores) para ajudar a entender os processos macro de um modelo de IC: demanda, produção e influencias (dos produtos). As demandas referem-se às requisições por informações solicitadas pelos usuários, aos tipos de requisitos e volumes. Os processos que sustentam a produção referem-se à coleta de informações, seleção e geração de produtos da IC. As influências envolvem o acesso da relevância de produtos, a compatibilidade com as requisições dos usuários e as mudanças nas capacidades corporativas. Johnston de fato, concentra-se mais nos objetivos da função da inteligência, do que nos processos da prática operacional. Ainda assim, seu modelo é uma alternativa à proposta clássica dos processos de IC.

Na proposta de Correia (2006), os processos da IC são agrupados obedecendo à lógica clássica dos processos de IC, observada em Herring (1999). Os processos envolvem o (1) planejamento e direção da prospecção, em (2) fontes públicas de dados e em (3) fontes humanas especialistas. Os dados são (4) processados para gerar os produtos da inteligência, que são sequencialmente (5) divulgados na organização. Nesse ciclo de processos, a busca de informações nas bases cognitivas públicas e humanas é considerada processos autônomos do ciclo, não do estágio de coleta, aparentemente dando relevância a processos secundários.

O processo de Inteligência Competitiva desenvolvido por Rodrigues e Riccardi (2007), adaptado de Correia (2010), usa igualmente a lógica do processo clássico de Inteligência Competitiva, proposto original- 
mente por Herring. O modelo, porém, parece ser mais preciso e representativo do que os anteriores. Nesse modelo, a Inteligência Competitiva é (2) direcionada e planejada pelas (1) necessidades de informação da organização. As demandas assim definidas alimentam o (3) plano da prospecção. De forma planejada, as informações são buscadas em três fontes principais: as bases cognitivas públicas, as privadas e a base de especialistas. Tais informações são então (4) analisadas e selecionadas e é gerado um (5) produto do sistema de Inteligência Competitiva. Este produto é (6) disseminado junto às estruturas demandantes (administrativa, especialista e técnica) da organização.

\subsection{Usos de Inteligência Competitiva}

O produto da Inteligência Competitiva é utilizado nas organizações para diversas finalidades, podendo variar de acordo com o estágio de vida da organização ou sua caracterização. Os usos mais relevantes dizem respeito à produção de subsídios para a formulação de estratégias e às tomadas de decisão. Os usos também podem variar em empresas jovens, maduras ou mais avançadas no ciclo de vida empresarial.

\subsubsection{Formulação de Estratégias}

Tarapanoff (2001) defende que a gestão da informação e do conhecimento e a Inteligência Competitiva constituem, do ponto de vista teórico, uma nova metodologia, uma nova abordagem e síntese teórica, para o planejamento e administração estratégica das organizações e para a sua tomada de decisão.

Para formulação de estratégias, a principal função da Inteligência Competitiva é fornecer cenários prospectivos à organização. Cenários constituem uma ferramenta para ordenar a percepção sobre ambientes alternativos futuros, que orientam as decisões estratégicas da organização. Porter (1989) aponta cinco opções estratégicas para a empresa: a) formular estratégias para o cenário mais provável; b) apostar no melhor cenário para a empresa; c) definir a estratégia que produza resultados satisfatórios em todos os cenários; d) adotar uma estratégia flexível até que o cenário mais provável se torne aparente para a empresa; e) influenciar a ocorrência do melhor cenário; f) combinar algumas das alternativas anteriores. De toda sorte, sem cenários, possibilitados pela IC, não há formulação de estratégias eficientes.

Assim, o resultado final da elaboração dos cenários se transforma em subsídio para a continuidade da atividade de Inteligência Competitiva, que passa a monitorar os atores e as variáveis, acompanhar os sinais fracos e os fatores que podem levar à ruptura do contexto preponderante. Já, a utilização dos cenários fornecidos pela Inteligência Competitiva melhora a capacidade do administrador de agir proativamente na formulação de suas estratégicas com vistas à manutenção e ampliação de suas vantagens competitivas. (MARCIAL, 2001)

\subsubsection{Tomadas de Decisão}

Os tomadores de decisão processam informações recebidas da Inteligência Competitiva, de acordo com a qualidade de dados disponíveis, sua habilidade para acessá-los e sua capacidade de analisá-los. O sucesso de um gestor pode ser medido pela qualidade e quantidade de suas decisões acertadas, que vão depender de sua eficiência na utilização de informações. A chave para o sucesso é obter informações úteis e exatas disponíveis no momento certo. (BORGES, 2005)

Dentre as atividades da Inteligência Competitiva, uma das mais importantes consiste na identificação das necessidades de informação de modo a oferecer suporte aos processos decisórios (PRESCOTT, 2002). Tyson (1998) recomenda o uso de instrumentos de pesquisa para possibilitar a identificação das necessidades de informação dos gestores. O autor sugere que a Inteligência Competitiva deva dar suporte ao planejamento estratégico, atualizando-o sobre as mudanças ambientais, a competitividade e qualquer mudança que afete os "fatores críticos de sucesso" da organização, proporcionando uma estratégia atualizada.

Em ambientes incertos, decisões acertadas do passado tendem a ser repetidas preferencialmente a novas soluções, quando a organização não tem uma solução científica baseada em informações fidedignas. A Inteligência Competitiva está diretamente ligada à capacidade de coletar, armazenar e utilizar a informação pela organização. Assim, a necessidade de superar as incertezas ambientais requer das organizações o desenvolvimento de sistemas de Inteligência Competitiva. 
As disputas internas também afetam a capacidade de tomada de decisão das organizações. Adicionalmente, o estágio do ciclo de vida da empresa e a formação do corpo diretivo podem igualmente criar entraves estruturais às tomadas de decisão. Muitas vezes, os problemas não afetam apenas uma única área, tornando a decisão mais difícil, sem as informações adequadas. A Inteligência Competitiva exerce aí um papel crítico tanto nos processos decisórios, quanto nos de formulação de estratégias. (CASTRO; ABREU, 2006)

\subsection{Níveis de Maturidade do Processo de Inteligência Competitiva}

Rodrigues e Riccardi (2007) realizaram uma pesquisa entre as 500 maiores empresas sediadas no Brasil, por meio da qual identificaram o lócus funcional da IC, os objetivos, os motivos, as fontes, os processos, os usos, o papel da tecnologia da informação e o seu disciplinamento ético nessas organizações. Na referida pesquisa, as empresas apontam a hipercompetição como o principal motivo para implementar um sistema de Inteligência Competitiva. Aliada à hipercompetição, os objetivos estratégicos da empresa constituem um dos mais importantes fatores da existência e forma de funcionamento da IC.

A pesquisa de Rodrigues e Riccardi (2007) mostrou que a IC nessas empresas é ainda incipiente, de uma forma geral. Apenas 7\% das pesquisadas indicaram possuir formalmente sistemas de IC. Por outro lado, de alguma forma, todas as empresas pesquisadas possuem mecanismos internos de busca e análise de informações externas, que podem ser entendidos como mecanismos de IC. Tais mecanismos atribuem às atividades de inteligência, características de maior ou menor maturidade no uso e manipulação do sistema de IC. Com base nessas observações empíricas, os autores propõem um mapa de maturidade em uso da IC nas organizações. A Figura 1 mostra os diversos níveis de maturidade propostos.

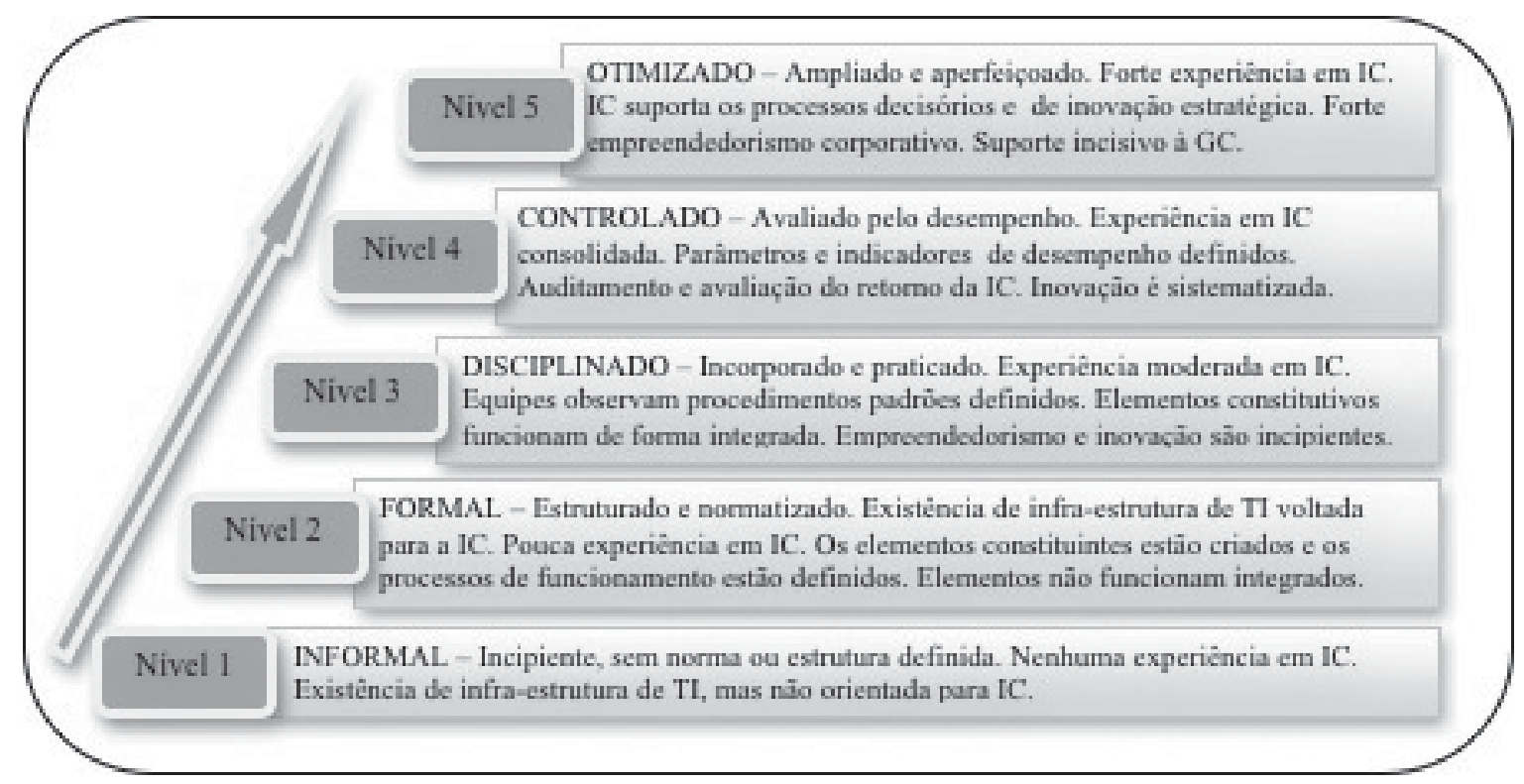

Figura 1: Níveis de maturidade em uso da Inteligência Competitiva

Fonte: Rodrigues e Riccardi (2007, p. 138)

Cada nível de maturidade possui características únicas e cada nível só é superado se todas as características daquele nível tiverem sido atendidas. A implementação de Inteligência Competitiva exige de seus responsáveis um árduo compromisso em normatizar e padronizar seus procedimentos com fins de ampliar a maturidade do sistema. Quanto maior o nível de ma- turidade do sistema, maior a capacidade competitiva da organização em função das informações providas.

A maturidade do sistema de Inteligência Competitiva varia entre os níveis (1) Informal e o nível (5) Otimizado. Para cada nível, há um conjunto de elementos específicos e caracterizantes que distinguem do próximo (RODRIGUES; RICCARDI, 2007). É com 
base nesse sistema de classificação da maturidade que se analisou o nível de maturidade da organização pesquisada.

\section{Metodologia de Pesquisa}

Para realização deste trabalho, o método escolhido foi o estudo de caso caracterizado pela análise em profundidade de um objeto ou um grupo de objetos, que podem ser indivíduos ou organizações. O estudo de caso como estratégia de pesquisa é um método que compreende o planejamento, as técnicas de coleta de dados e as abordagens de análise dos dados. (ACEVEDO; NOHARA, 2007)

O desenvolvimento de projetos de estudo de caso precisa maximizar as condições relacionadas à qualidade do projeto, como validade do constructo, validade interna (apenas para estudos causais ou explanatórios), validade externa e confiabilidade (YIN, 2005). O estudo de caso pode ser aplicado em casos decisivos ao testar uma teoria bem-formulada ou em casos raros ou extremos. Também é aplicável em casos representativos, típicos, reveladores ou longitudinais. O estudo de caso, nesse sentido, deve ser conduzido de maneira assertiva, segundo um protocolo de pesquisa, de modo a garantir esses pontos fundamentais.

Os dados coletados por entrevistas semiestruturadas foram submetidos à análise de conteúdo, para que fossem identificados os conceitos que constituíram as bases para responder à pergunta de pesquisa e aos objetivos específicos desse trabalho. Essa análise permitiu o estudo dos conteúdos conceituais mais significativos para descrever e explicar o objeto do estudo, de modo a proporcionar uma resposta de caráter científico à pergunta inicial.

A seleção do caso respeitou a aderência do perfil da organização à questão a ser estudada - grau de maturidade em uso da IC. Buscou-se, então, identificar as pessoas envolvidas nos processos de Inteligência Competitiva dentro da organização pesquisada para selecioná-los como sujeitos sociais do presente estudo.

Para a coleta de dados, elaborou-se o instrumento de coleta, um roteiro de entrevistas, estruturado, porém aberto, segundo a lógica dos elementos caracterizantes de cada nível de maturidade presentes no modelo de Rodrigues e Riccardi (2007). As perguntas elaboradas tinham como objetivo identificar as bases do objeto estudo e dar subsídio para responder aos objetivos do presente estudo: caracterização do nível de maturidade em uso da IC. O instrumento de pesquisa foi submetido a um pré-teste para avaliação da adequabilidade das perguntas em relação aos objetivos da pesquisa, seu encadeamento lógico e sua inteligibilidade pelos futuros sujeitos sociais da pesquisa. Foram selecionados os Gerentes executivos de quatro áreas da organização: Comunicação e Marketing; Segurança Empresarial; Relações Internacionais; e Gestão de Riscos de Ativos.

Os dados obtidos foram processados e submetidos à análise de conteúdo, que consiste numa técnica "[...] que faz inferências através da identificação sistemática e objetiva de características específicas de mensagens" (SELLTIZ, 1987, p. 101). Os passos da análise de conteúdo são: escolha de um fenômeno (que será codificado), seleção o meio de comunicação à partir do qual serão feitas as observações, derivar as categorias de codificação, definir a estratégia de amostragem, treinar os codificadores e análise dos dados. Selltiz (1987) afirma que a análise da comunicação envolve a amostragem de fontes (jornais e revistas a serem analisados, por exemplo), amostragem de data (a qual período refere-se o estudo) e amostragem de unidades (os aspectos da comunicação que serão analisados).

\section{Análise e Interpretação dos Resultados}

A análise dos dados coletados baseia-se na interpretação da maturidade em uso da Inteligência Competitiva, segundo os cinco níveis de maturidade, propostos na obra de Rodrigues e Riccardi (2007). Cada nível de maturidade é caracterizado por meio de quatro a seis parâmetros distintos. Cada coleta de dados realizada segundo o protocolo da pesquisa obedeceu à busca destes parâmetros com o objetivo de identificar o nível de maturidade em uso do Sistema de Inteligência Competitiva nas quatro áreas estudadas da organização. Para identificação do nível de maturidade foi utilizada convencionalmente a seguinte regra: o nível foi considerado satisfeito quando todos os seus componentes estiverem presentes nos dados coletados em cada área. Os elementos e o critério de análise foram subtraídos do conhecimento dos sujeitos sociais, 
no momento da entrevista, para garantir isenção de vieses nas respostas.

\subsection{Inteligência Competitiva na Área de Comunicação e de Marketing}

A área de Comunicação e Marketing foi selecionada por causa de sua responsabilidade pela elaboração dos clippings diários de notícias que circula entre todos os gerentes da organização. Identificou-se que aí, a coleta das informações acontece via subcontratação de uma empresa de serviços especializados em informações de entorno. "Foi contratada uma empresa que coleta diariamente nos meios de comunicação impresso e em tempo real na Internet as notícias que contenha palauras chaves específicas, tais como o nome da instituição financeira, os principais concorrentes e os principais produtos, serviços e programas administrados pela instituição", relata a executiva. A área de marketing serve os gestores nacionais de produtos ou serviços. Por isso, esses gestores podem demandar à área de marketing a alocação de novas palavras chaves para subsidiar o desenvolvimento de um novo produto ou para subsidiar a realização de num novo projeto.

Segundo a entrevistada, não é a sua área, porém, que faz a seleção primária das informações coletadas. A própria empresa contratada faz a seleção, a partir de um filtro macro, preestabelecido, de modo a identificar se as informações coletadas realmente têm ligação com os interesses da organização solicitante. As informações recebidas são então transpostas para uma base eletrônica e encaminhadas às mais variadas áreas da organização, desde os gestores da Matriz às unidades de ponta, como forma de municiá-los de informação sobre os movimentos do mercado.

As atividades acima descritas, contudo, não são vistas como um Sistema de Inteligência Competitiva, ou mesmo como parte dele. Não se percebe uma ligação direta dessa atividade com a formulação de estratégias institucionalizadas ou tomadas de decisão macro na organização, a não ser quando a coleta ocorre por demanda de um gestor estratégico ao definir um novo conceito a ser pesquisado. Em geral, tais informações servem tipicamente a interesses táticos, das várias gerências $e$, principalmente, como instrumento de orientação das campanhas de comunicação e marketing da organização. Adicionalmente, de acordo com a entrevistada, "o suporte de Tecnologia de Informação para realização dessas atividades é mínimo, pois a coleta e tratamento são feitos fora da organização, por uma agência de comunicação contratada para essa finalidade".

Um formulário eletrônico circulante é o único produto dessa atividade e "não possui tipicamente um caráter recomendativo", afirma a Gerente Executiva. Esse formulário não é avaliado ou auditado pelo seu conteúdo. O controle se estabelece somente no nível de verificação da realização diária da tarefa pela empresa contratada. Não há, igualmente, identificação ou relação direta dessa atividade com a Gestão do Conhecimento na organização.

A experiência em uso de Inteligência Competitiva na área de Comunicação e Marketing, na visão da entrevistada, é bastante incipiente e informal. Nenhum dos elementos caracterizantes dos níveis dois ao cinco foi identificado, exceto os elementos do nível 1 (INFORMAL). A informalidade institucional da IC nessa área pesquisada deve ser entendida em termos de inexistência de processos formais e da inexistência da responsabilidade atribuída na estrutura formal da organização, não necessariamente de sua existência. De fato, a atividade de prospecção é realizada de forma terceirizada, mas sua real utilidade não é avaliada. É apenas controlada a execução da tarefa, não sua serventia funcional ou estratégica. Assim, a atividade transforma-se apenas numa tarefa de execução protocolar (contrato), sem aprendizado e incorporação institucional na organização.

Os produtos fornecidos não guardam necessariamente relação com as necessidades de quem os recebe, pois os critérios de busca são fixos e padronizados, ressaltando o caráter genérico das informações, que carecem de caráter recomendativo. $\mathrm{O}$ processo mais estruturado e sistematizado na área diz respeito à coleta direcionada, quando há solicitação por parte de algum gestor de cargo estratégico, por informações específicas de algum produto concorrente ou da linha de comunicação das organizações concorrentes.

\subsection{Inteligência Competitiva na Área de Segurança Empresarial}

A segunda área de coleta de dados foi a área de Segurança Empresarial. A seleção dessa área se deu 
em virtude da existência de uma Gerência de Inteligência Competitiva. A área é composta por pessoas pertencem ao corpo funcional da organização, porém originárias de áreas distintas, constituindo assim, um grupo multifuncional e interdisciplinar.

Os processos de Inteligência Competitiva desenvolvidos na área dizem respeito mais à Inteligência de Segurança do que à Competitiva ou Empresarial. A coleta de dados se restringe a fontes abertas (mídia, internet e FEBRABAN), ao estudo de cenários, à produção de conhecimento com foco na recomendação e sinalização de posturas e fatos que podem vir a acontecer, mas que dizem respeito à segurança das pessoas e dos processos em uso na organização pesquisada. Muitas vezes, segundo os dados oriundos de fontes abertas precisam ser complementados por informações de outras entidades, como a Polícia Federal, para obtenção de maiores detalhes e maior alcance recomendativo e preventivo.

Segundo o entrevistado, "o principal produto da Inteligência são relatórios, alertas e informes que visam gerar uma cultura de segurança preventiva, evitando fatos indesejados". Segundo avaliação da área, "algumas ocorrências foram evitadas graças a esses instrumentos, gerando o reconhecimento às pessoas e as atividades de Inteligência da Segurança Empresarial. Os principais resultados são a preservação das pessoas e do patrimônio da organização, evitando traumas e prejuízos".

Apesar de os processos serem definidos, eles possuem normatização ainda básica e em desenvolvimento. Por isso, tais atividades ainda não são reconhecíveis em seu grau de importância para os negócios. Segundo o Gerente Executivo, responsável pela Inteligência da organização,

A falta de uma área central de Inteligência Competitiva na organização faz com que as estruturas de Inteligência Competitiva alocadas em algumas áreas da empresa não tenham a visibilidade e a importância necessárias. Parece ainda não estar claro para organização, a importância e o caráter estratégico das atividades de Inteligência da Segurança Empresarial para as ações mercadológicas da organização. Contudo, em virtude das prevenções orientadas por essa área para a organização, percebe-se uma valorização da Gerência de Inteligência Competitiva em Segurança Empresarial, com a definição de implementação de uma estrutura mais adequada e um sistema corporativo de TI para auxiliar no armazenamento, processamento, gestão $e$ tratamento dos dados.

A Gerência de Inteligência Competitiva não possui, segundo informações do entrevistado, uma rotina ou processo parametrizado de avaliação de desempenho, nem muito menos uma auditoria interna ou externa sistematizada para controlar a eficiência de seus processos.

Todos os elementos caracterizantes do nível 2 (FORMAL) foram identificados. Em termos de experiência em IC considerou-se que essa seja Moderada, em virtude das atividades desenvolvidas de maneira permanente na área, em virtude da prática e do conhecimento teórico instalado. É importante que se note que "Experiência Moderada em IC" é um dos componentes do Nível 3 (DISCIPLINADO).

\subsection{Inteligência Competitiva na Área de Relações Internacionais}

Segundo a Gerente Executiva da Área de Relações Internacionais, a partir de 2005, a instituição começou a se internacionalizar com base em três eixos de atuação: comércio exterior, cooperação técnica e remessas e captação de recursos. Como novo entrante no mercado internacional, a Gerente argumenta a implantação das atividades de inteligência competitiva, pois

[...] a instituição precisou mapear todos os concorrentes, sua atuação, estratégias, clientes e números alcançados. Estruturou-se, então, uma equipe de Inteligência Competitiva para identificar dados relevantes que poderiam ser transformados em informação para a tomada de decisão. Com essa finalidade, foi criado o produto "Relatório de Prospecção" dirigido aos gerentes e superintendente da unidade [...]. Entretanto, a instituição .não possui um sistema integrado de inteligência. Várias são as ações para identificação e controle da informação, às vezes configurando retrabalho, mas não há, ainda, uma gestão centralizada que tenha como meta a agregação de valor às informações coletadas, atendimento personalizado e proatividade.

A informação de entorno tem muito valor para a organização e sempre que está disponível é usada como base para a tomada de decisão e para a formu- 
lação de estratégias. Mas o desafio é tornar o acesso e uso dessas informações uma rotina para os executivos. "A quantidade enorme de informações recebidas no dia a dia e a falta de um sistema centralizado e reconhecido como eficaz, seguro e tempestivo atrapalham a escolha da 'boa' informação [...]", afirma a entrevistada. Muitos relatórios estratégicos deixam de ser lidos e decisões deixam de ser tomadas com a antecedência que o mercado competitivo requer, às vezes por causa do excesso de informações, às vezes por falta delas.

$\mathrm{Na}$ área de Relações Internacionais, a equipe de IC é formada por duas pessoas, um especialista e um gerente. Contudo, a mesma equipe também é responsável pelas atividades de cooperação técnica internacional, inequalisando o trabalho nos dois setores. À medida que a demanda por um grupo de atividades cresce, o outro fica prejudicado. Segundo a entrevistada, no ano de 2006, início das atividades de IC, foram produzidos 51 relatórios (produtos de IC), contra apenas $11 \mathrm{em} 2010$, onde se intensificaram as atividades de Relações Internacionais.

Segundo a executiva, "[...] a realização das atividades é essencialmente manual, não havendo um sistema informatizado para tal finalidade. A gestão da informação é muito precária, sem controle nem preocupação pela sua memória. Relatórios anuais são produzidos, mas as informações não são usadas para constituir um banco de inteligência ou de conhecimento". Não existe rotina definida de avaliação dos produtos da IC na área, nem de seu processo, muito menos de auditoria interna ou externa.

A experiência em uso de IC na área de Relações Internacionais começa a ser construída e busca a sua institucionalização, pois já possui certo grau de formalização. A carência de normas escritas integradas aos processos de tecnologia da informação parece ser o principal entrave à institucionalização do sistema. Em função do conhecimento existente na área, relativo aos processos de prospecção e da realização das atividades de forma operacional padronizada e constituída, mesmo sem o aparato tecnológico necessário, parece haver nessa área maior formalização das atividades de inteligência competitiva.

\subsection{Inteligência Competitiva na Área de Gestão de Riscos de Ativos}

A área de Gestão de Riscos de Ativos é responsável pela avaliação os riscos relacionados aos ativos que compõem as carteiras de investimento, onde são alocados recursos de terceiros. As decisões de gestores e administradores dessas carteiras são tomadas com base nos relatórios elaborados da área de Gestão de Riscos de Ativos. Isso denota a importância de sua atuação como geradora de informações para a formulação da estratégia e a tomada de decisão dos gestores e administradores das carteiras de investimentos, de acordo com o Gerente Nacional da área. Segundo o entrevistado, em relação às atividades de IC,

[...] a que mais se identifica com a Inteligência Competitiva é a avaliação dos riscos e o acompanhamento dos cenários. A avaliação dos riscos depende diretamente da coleta de informações das mais variadas fontes públicas e privadas. Essas informações são armazenadas em um banco de dados, para que sejam avaliadas. Os resultados provenientes desta avaliação das informações são estruturados e servem de parâmetro na avaliação dos riscos de cada ativo. Os cenários prospectivos também sofrem o mesmo processo.

O produto da Inteligência Competitiva em Gestão de Riscos de Ativos serve diretamente como base para a tomada de decisão dos gestores e administradores destes ativos. Contudo, como as atividades acima descritas, não são a única atribuição das pessoas envolvidas, não se pode caracterizar a área como um setor voltado exclusivamente à IC, como percebido na área de Segurança Empresarial. Ademais, não existe uma postura institucionalizada da organização pesquisada em prol da formalização funcional e hierarquização dessas atividades no organograma da organização.

Na área de Gestão de Riscos de Ativos não existe parametrização e normatização das atividades ligadas à IC. Existe, entretanto, a consciência de que muitos de seus processos e atividades são, de fato, processos de IC. A falta de norma escrita, definição de processos $e$ atividades exclusivas de inteligência competitiva, porém, caracteriza este como um sistema mais infor- 
mal. A área envolve a participação de oito pessoas do corpo funcional, provenientes de várias áreas, como Tecnologia da Informação, Controladoria, Estatística e Distribuição, de maneira informal, isto é, mais em caráter voluntário. De acordo com a função ou cargo desempenhado em seus setores de origem, bem como sua senioridade na área, essas pessoas assumem papéis e atribuições nas tarefas de inteligência, contudo, sem uma padronização ou formalização institucional.

Todos os desenvolvimentos tecnológicos da área, como planilhas e softwares simplificados são desenvolvidos na própria área de inteligência, o que caracteriza a não interferência da área de Tecnologia da Informação nas atividades de IC da área de Riscos. Segundo o Gerente de Riscos e Ativos,

[...] a coleta de dados da área se dá através de buscadores de informações abertas e públicas, atas de reuniões com representantes do mercado, com órgãos de auto-regulação, com indivíduos do mundo acadêmico, além de outros meios mais tradicionais como jornais e revistas especializadas. As informações são confrontadas com outras fontes, para apurar sua fidedignidade e realizar acompanhamento contínuo.

As informações assim obtidas são repassadas aos gestores e administradores através do relatório de riscos e do relatório da área econômica, presencialmente, nas instâncias decisórias da área. Esses relatórios têm um caráter recomendativo quanto às decisões de escolha e negociação dos ativos das carteiras. Isso significa que a alocação de recursos, a projeção de cenários e o controle dos riscos sofrem influência direta das informações dos relatórios da IC. Contudo, de acordo com o Gerente Nacional, "não existe uma avaliação formal e parametrizada dos resultados diretos destas atividades".

Os dados coletados na área de Gestão de Riscos de Ativos sugerem uma experiência incipiente no uso de Inteligência Competitiva, por causa da não identificação dos profissionais que desempenham atividades ligadas às questões de Inteligência Competitiva. A experiência existente é pouca, advém da prática e não do acúmulo do conhecimento formalizado na área. Como não existe normatização, padrões e elementos definidos, a atuação da inteligência competitiva nessa área é decorrente exclusivamente da operacionalização dos processos de forma voluntária sem, contudo, visar à sua fundamentação e ao seu alcance institucional.

Os produtos fornecidos pela área cumprem seu papel junto aos usuários da área de Riscos de Ativos. Poderiam ter um alcance maior se fossem institucionalizados, graças à estruturação de seus processos e de seu sistema. A Tecnologia de Informação poderia dar maior eficiência aos processos e também aos produtos da IC se fosse usada de forma sistêmica. A IC de Riscos de Ativos poderia, desta forma, dar também melhores condições e subsídios técnicos aos tomadores de decisão e aos formuladores de estratégias organizacionais.

\subsection{Mapa Organizacional do Nível de Maturidade em Uso de IC}

A partir da atribuição dos níveis de maturidade em uso de IC em cada área da organização, procedeu-se à elaboração de um mapa geral para visualização da maturidade em IC nas áreas estudadas. O mapa apresentado não necessariamente reflete a realidade da IC na organização como um todo, mas permite uma visão integrada do status de manejo da IC na organização pesquisada, pois a pesquisa focou as áreas consideradas mais proeminentes na estrutura de negócios da organização. Outras áreas, de menor importância, não fogem à realidade aqui demonstrada. O Quadro 1 mostra o mapa resultante da integração dos dados da pesquisa.

O Quadro 1 apresenta o mapeamento dos componentes resultantes dos dados da pesquisa visando à determinação subjetiva do grau de maturidade em uso de IC nas quatro áreas pesquisadas da organização. É possível visualizar pelo menos duas características importantes, presentes na estrutura da IC nas áreas pesquisadas. A primeira refere-se à normatização dos processos de IC. Com exceção apenas da área de Segurança Física, que inicia a normatização de seus processos, todas as outras áreas carecem de normatização. A segunda refere-se à virtual ausência da Tecnologia da Informação no suporte às atividades de IC. Apesar dessa ausência, que interfere na produtividade das atividades de IC, os processos existentes, tipicamente manuais, compensam, no entanto, a evidência da prática. É importante notar-se também que a eficiência e a gradual institucionalização da IC na organização dependem, intrinsecamente, destes dois fatores. 


\begin{tabular}{|c|c|c|c|c|c|}
\hline Nivel & Componentes & $\begin{array}{l}\text { Marketinge } \\
\text { Comunicaţo }\end{array}$ & $\begin{array}{l}\text { Segurangha } \\
\text { Fisica }\end{array}$ & $\begin{array}{l}\text { Relogöes } \\
\text { Internacionais }\end{array}$ & $\begin{array}{c}\text { Gestio de } \\
\text { Biscos de Ativos }\end{array}$ \\
\hline & Nivel identificado & 1-Informal & 2-Formal & 2 - Formal & 1-Informal \\
\hline \multirow{4}{*}{ 1- Informal } & Sem norme escrita & & & & \\
\hline & Estrutura indefinidh & & & & \\
\hline & Nenhuma experiènci em IC & & & & \\
\hline & TI nâo orientada à IC & & & & \\
\hline \multirow{6}{*}{2 - Formal } & Noms escrita & & & & \\
\hline & Estrutura definida & & & & \\
\hline & TI crientada à IC & & & & \\
\hline & Pouca Experiènci em IC & & Moderada (3) & Moderada (3) & \\
\hline & Elementos e processos criados $e$ definidos & & & & \\
\hline & Elementos nào integrados & & & & \\
\hline \multirow{5}{*}{3 - Disciplinado } & Incorporado e praticado & & & & \\
\hline & Experiëncia Moderada cm IC & & & & \\
\hline & Procodimentos padrùes definidas $c$ observados & & & & \\
\hline & Elementos integrados & & & & \\
\hline & Emoreendedorismo $\mathrm{e}$ Lnovaçã̃o ixcipientes & & & & \\
\hline \multirow{5}{*}{ 4. Controbido } & Avaliaçào de desempenho & & & & \\
\hline & Experiëncia Consolidada cm IC & & & & \\
\hline & Paràmetros e indicadores de descmpenho & & & & \\
\hline & Aaftori e avaliaçầ de retarmo du IC & & & & \\
\hline & Inovaçào sistematizad & & & & \\
\hline \multirow{5}{*}{ 5. Otimíado } & Amplado e aperficicoado & & & & \\
\hline & Forte Experiéncia em IC & & & & \\
\hline & IC suporta processos decisórics e incraçào estratégica & & & & \\
\hline & Forte empreendedorismo corporativo & & & & \\
\hline & Suporte incisivo à Gestâo do Conhecimento & & & & \\
\hline
\end{tabular}

Quadro 1: Mapa dos Níveis de Maturidade em Uso de IC nas Áreas Estudadas

Fonte: Elaborado pelos autores deste artigo

Em termos do grau da experiência no uso da IC, pode-se dizer que este varia de pouca experiência a experiência satisfatória, na visão dos próprios entrevistados.

\section{Conclusões}

Com base na coleta de dados realizada e discutida, foi possível estabelecer o nível de maturidade em uso de Inteligência Competitiva nas áreas pesquisadas da empresa, de acordo com o modelo e parâmetros propostos por Rodrigues e Riccardi (2007). Em virtude da constatação de níveis de maturidade diferentes nas áreas pesquisadas, constata-se que a Inteligência Competitiva apresenta-se estruturalmente dispersa $e$ não unificada na organização.

A realização desta pesquisa demonstrou que a classificação de níveis de maturidade em uso de Inteligência Competitiva, proposta por Rodrigues e Riccardi
(2007) é passível de aplicação nos estudos empíricos e contribui para a compreensão das características de funcionamento dos Sistemas de IC das organizações. Em decorrência de estudos dessa natureza, é possível também estabelecer as relações entre o nível de maturidade em uso da IC e a relevância dos produtos da IC para os usuários ou seus demandantes internos. Isso fixou evidente como um colateral dessa pesquisa. Nas áreas em que as atividades de IC estão terceirizadas, como no caso da área de Comunicação e Marketing da organização pesquisada, e em que pouca importância é dada à sua função institucional, a eficiência de seus produtos e sua influência nos processos decisórios e de formulação de estratégia é, evidentemente, baixa. Em outras áreas, como é o caso da área de Segurança Física, em que se articula de maneira mais consistente, demonstrando seu valor circunstancial e estrutural para o negócio da organização, no entanto, adquire maior importância e passa a ser incorporada na estrutura hierárquica da organização. 
Este estudo, porém, assenta-se sobre a caracterização dos níveis de maturidade de forma subjetiva, como uma visão dos sujeitos sociais envolvidos no processo, mas sem uma escala mais objetiva de avaliação. Sugere-se, portanto, que estudos futuros devam se preocupar com a elaboração de uma metodologia que permita a identificação objetiva das características e do respectivo nível de maturidade em uso da IC, em organizações. Sugere-se, ademais, que estudos futuros verifiquem a hipótese da relação entre o nível de maturidade em uso de IC e seu desempenho operacional, lucrativo ou de participação no mercado.

\section{RefERÊNCIAS}

ABRAIC - ASSOCIAÇÃO BRASILEIRA DE ANALISTAS DE INTELIGÊNCIA COMPETITIVA. Sobre a ABRAIC. [2010]. Disponível em: <http://www.abraic.org.br>. Acesso em: 18 out. 2010.

\section{ACEVEDO, C. R.; NOHARA, J. J. Monografias no} curso de administração: guia completo de conteúdo e forma. 3. ed. São Paulo: Atlas, 2007.

BORGES, M. E. N. A Informação como recurso gerencial das organizações na sociedade do conhecimento.

Ciência da Informação. Brasília, DF, v. 24. n. 2, p. 181188, 1995.

CASTRO, J. M.; ABREU, P. G. F. Influência da inteligência competitiva em processos decisórios no ciclo de vida das organizações. Ciência da Informação, v. 35, n. 3, p. 15-29, set.-dez. 2006.

COELHO, Gilda M.; DOU, Henri; QUONIAM, Luc; SILVA, Cícera H. Ensino e pesquisa no campo da inteligência competitiva no Brasil e a cooperação francobrasileira. Revista Hispana de La Inteligencia Competitiva - Puzzle. España, año 6, n. 23, p. 12-19, 2006.

COMBS, Richard E. The competitive intelligence handbook. Metuchen: Scarecrow, 1992.

CORREIA, C. C. Getting Competitive. [2010]. Disponível em: <http://www.libraryjournal.com/lj/ljinprint/ currentissue/866008-403/getting_competitive.html.csp>. Acesso em: 13 set. 2010.
DAVIS, I.; STEPHENSON, E. Ten trends to watch in 2006. The Mckinsey Quarterly. 2006. Disponível em: <https://www.mckinseyquarterly.com/Ten_trends_to_ watch_in_2006_1734>. Acesso em: 15 jan. 2010.

EISENHARDT, K. M. Building Theories from Case Study Research. Academy of Management Review, Briarcliff Manor, NY, v. 14, n. 4, p. 532-550, 1989.

FULD, L. M. The new competitor intelligence: the complete resource for finding, analyzing and using information about your competitor. New York, John Wiley \& Sons, 1995.

GOMES, E.; BRAGA, F. Inteligência competitiva. Rio de Janeiro: Elsevier/Campus, 2002.

Inteligência Competitiva no Brasil: uma realidade corporativa. Revista Hispana de La Inteligencia Competitiva - Puzzle, España, ano 6, n. 23, p. 5-10, ago.-out. 2006.

HAGEL III, J. Pensando fora do quadrado. Rio de Janeiro: Campus, 2003.

HAMEL, G. Leading the revolution. Boston (MA): Harvard Business Review Press, 2000.

HITT, M. A.; IRELAND, R. D.; HOSKISSON, R. E. Administração estratégica: competitividade $e$ globalização. São Paulo: Pioneira, 2002.

JOHNSTON, R. Analytic culture in the US intelligence community: an Ethnographic Study. Washington: Center for the Study of Intelligence. Central Intelligence Agency. 2005.

MARCIAL, E. C.; COSTA, A. J. L. O Uso de Cenários Prospectivos na Estratégia Empresarial: vidência especulativa ou inteligência competitiva. In: ENCONTRO DA ASSOCIAÇÃO NACIONAL DE PÓS-GRADUAÇÃO E PESQUISA EM ADMINISTRAÇÃO, 25., 2001, Campinas. Anais... Campinas: ANPAD, 2001.

PINTEC - PESQUISA DE INOVAÇÃO TECNOLÓGICA. Publicação PINTEC 2008. Disponível em: <http:// http://www.pintec.ibge.gov.br/index.php?option=com_con tent\&view $=$ article\&id $=45 \&$ Itemid $=12>$. Acesso em: 21 mar. 2011. 
PORTER, M. Estratégia competitiva. Rio de Janeiro:

Campus, 1989.

Vantagem competitiva: criando e sustentando um desempenho superior. 17. ed. Rio de Janeiro:

Campus, 1989.

PRESCOTT, J. E.; MILLER, S. H. Inteligência

competitiva na prática. Rio de Janeiro: Campus, 2002.

RODRIGUES, L. C.; RICCARDI, R. Inteligência

competitiva: para negócios e organizações. Maringá, PR:

Unicorpore, 2007.

SCIP - SOCIETY OF COMPETITIVE INTELLIGENCE

PROFISSIONALS. About SCIP. [2010]. Disponível em:

$<$ http://www.scip.org >. Acesso em: 18 jul. 2010.

SELLTIZ, C. et al. Métodos de pesquisa nas relações

sociais. 2. ed. São Paulo: E.P.U. 1987. v. 2, 3.

TARAPANOFF, K. (Org.). Inteligência organizacional

e competitiva. Brasília, DF: UnB, 2001.

TYSON, K. W. M. The complete guide to competitive intelligence. Chicago: Kirk Tyson International, 1998.

WEISS, Arthur. A brief guide to competitive intelligence: how to gather and use information on competitiors.

Business Information Review, v. 19, n. 2, p. 38-47, jun. 2002.

YIN, R. Estudo de caso: planejamento e métodos. 3. ed.

Porto Alegre: Bookman, 2005. 